\section{THE ESSO REFINERY, FAWLEY}

$A \mathrm{~T}$ the beginning of July 1949 a site of 450 acres A near the village of Fawley, Hampshire, was still covered with rolling wood and farmland. In November 1951, less than two and a half years later, a vast level plain had replaced the farms and from

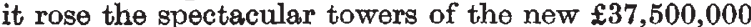
oil refinery built for the Esso Petroleum Company. By that date 97.48 per cent of the work on the new refinery had been completed. Most of the major process units had been in operation since July 1951, yet the original date set for the completion of this undertaking, the largest oil refinery ever built at any one time anywhere in the world, had been January 1952. This was a tremendous achievement from many points of view - technical, financial, economic and social.

The refinery was built by a combination of American management and British labour. The Productivity and Technical Assistance Division of the Mutual Security Agency Mission to the United Kingdom wished to determine the nature of the management policies and practices responsible for the unusually rapid construction of the refinery. A report, prepared by A. D. Gray and Mark Abrams, of Research Services, Ltd., aroused such wide interest that it has now been made available to the British Institute of Management for general publication.

The investigators were asked to discover how far and in what ways management organization and policy and labour-management relations had contributed to the unexpectedly high productivity of the men on the job. The report shows that the factors which enabled the construction of the refinery to be completed well ahead of the date originally scheduled include both fortuitous external circum. stances and particular techniques of organization and management employed by those responsible for the job. The main favourable external circumstances were: (1) dollars were available for the purchase of materials and equipment in the United States; (2) at the time that initial orders were placed, materials were readily available in the United States; (3) the size and importance of the refinery were exceptional and this helped to create a favourable psychological atmosphere. Moreover, a man of outstanding ability had been chosen as the project manager, capital equipment was on a generous scale, suppliers made extra efforts to supply materials both from realization of the refinery's importance and in anticipation of future orders, and workers took pride in working on the project; (4) because of its special dollar-saving importance to the British economy, the job had the support of the British Government, which assisted in obtaining priorities for materials purchased in Great Britain.

Not all the circumstances were favourable, however. There was, for example, a shortage of skilled labour both in the area and in the country as a whole; the site was far removed from populated areas ; there was a virtual absence of normal transport facilitios; and working conditions on the site proved particularly difficult. Yet the task was completed before the agreed time.

The observers made a special study of the specific managerial and organizational practices which contributed to the speedy construction of the refinery. These were reported as follows. There was, first, close co-operation between contractor and client. The Esso Petroleum Co. had senior representatives always on the site, both to inspect the work and for immediate consultation on matters on which the approval of the client was required.

Secondly, detailed plans were prepared at an early stage. All the ordering of materials was done from these plans. The technical resources of Esso's affiliated company, Standard Oil Development, and particularly its extensive records and experience of the construction of refineries, were drawn upon in estimating supply and labour needs.

Thirdly, materials were ordered early.

There was, in addition, a vigorous scheme for expediting deliveries, as well as a system of coding orders, deliveries and allocation of all materials according to the units where they were required, so that both the supply and cost situation for any unit could be quickly ascertained. A monthly report showed the actual and scheduled progress and there was continuous inspection of the site by top management. A system of communications was developed to ensure that all in authority were informed of everything that affected the whole job. Most important, engagement of all labour was under one contract drawn up with the Confederation of Shipbuilding and Engineering Unions. This resulted in a unified system of wages for all crafts. A system of supervision was organized which made it the primary responsibility of supervisors to see that work was not interrupted through lack of materials, labour or skill; special measures were taken to reduce absenteeism.

A valuable means of eliminating difficulties was the formation of a site executive committee of shop stewards and management representatives to settle problems about working conditions on the site. The management was adamant in refusing to allow labour disputes to be discussed except through official trade union channels; this led to a considerable strengthening of the 'powers' of shop stewards. One contractor was made responsible for the major part of the work and the number of sub-contractors was reduced to a minimum. This simplified the problems of co-ordination and made possible a streamlined system for the control of progress and supplies; it also facilitated the most effective and economical use of labour, and greatly assisted trade unionmanagement negotiations. $\quad$ T. H. HawkINs

\section{PROBABLE OBSERVATION OF THE GALACTIC NUCLEUS AT 400 Mc./s.}

\section{By R. X. McGEE and J. G. BOLTON}

Division of Radiophysics, Commonwealth Scientific and Industrial Research Organization, Sydney, N.S.W.

$\mathrm{W}$ $\mathrm{E}$ have recently made a survey of the central section of the Milky Way using a pencil-beam aerial at a frequency of $400 \mathrm{Mc} / \mathrm{s}$. The survey covered the zone of the celestial sphere from - $17^{\circ}$ to $-49^{\circ}$ in declination and approximately $15 \mathrm{hr}$. to $20 \mathrm{hr}$. in right ascension. The aerial reflector, a paraboloid of revolution of aperture diameter $80 \mathrm{ft}$. and focal length $40 \mathrm{ft}$., is hollowed out of the earth ; its surface is consolidated with concrete and covered with half-inch mesh wire-netting. The feed consists of a wide-band dipole and plane reflector supported on an aluminium mast. The aerial beam-width is $2^{\circ}$ between half-power points at $400 \mathrm{Mc} / \mathrm{s}$., and the beam can be directed by tilting the mast in the meridian plane. The relation between the angle of 